\title{
Pain in cancer patients with advanced stage disease
}

\begin{abstract}
Oncologic pain is a predominant symptom who affects oncological patients with advanced disease; the interconnected symptoms are perceived and experienced in a unique way. The patient/caregiver must recognise and describe their own experience of pain, in order to occur the process of capacity for pain management, at home. Recognition of pain, to name and identify characteristics and factors that influence and are part of the experience of disease will be the first step to the involvement of patient/caregiver during the process of care.
\end{abstract}

Keywords: pain, oncologic pain, educational program, training, cancer patient with advanced disease
Volume 2 Issue I - 2018

Isabel Bico, Manuel José Lopes

Nursing department, University of Évora, Portugal

Correspondence: Isabel Bico, Nursing department, Universidade de Évora, Escola Superior de Enfermagem de São João de Deus, Professora Adjunta, Portugal, Email imtb@uevora.pt

Received: November 17, 2017 | Published: January 08, 2018

\section{Introduction}

Oncologic pain, in some situations, happens quickly. The transition for a process of advanced disease may occur during the state of diagnosis, state of treatment, because of the ineffectiveness of the treatment, or afterwards in a case of relapse. The pain is defined by International Association for the Study of Pain (IASP), as "an unpleasant sensory and emotional experience associated with actual or potential tissue damage, or described in terms of such damage". ${ }^{1}$ The pain is a vital sign whose manifestation leads to the search of health care. In this way is of great importance as warming signal of physiological, psychological, social or spiritual change, in a latent state. No pain control may be the cause of pathophysiologic dysfunctions which lead to physical, psychic, social and spiritual changes that affect patient and caregiver.

The pain is the more frequent symptom of oncologic disease. In advanced state, can become a chronic pain which cause a big suffering for patient and feelings of hopelessness to the caregiver. According to Palliative Care in European, oncologic pain, often considered as the main cause of chronic pain, represents a small percentage of patient's affected by chronic pain. However, have an increasingly importance because represents the second cause of deaths in Portugal and there is moderate to severe pain in more than $90 \%$ of patients with terminal cancer. ${ }^{2}$ The control of pain is a crucial tool for the comfort of patient and caregiver. The development of an educational programme to qualify the patient for pain management could have a positive impact on pain control. ${ }^{3}$ Recognize pain and the way how one interact with it, will be the first step for knowledge and skills development, essential for capacitation process. ${ }^{4,5}$ This work follows on the nursing $\mathrm{PhD}$ project, a broader study on the evaluation of the effect of an educational program on the oncologic patient/caregiver with advanced disease for the management of the pain at their household. Therefore, the following question was placed: "How would you describe your pain?" To acknowledge one's pain and understand how one relates to it will be the first step towards the development of knowledge and skills essential to the training process.

\section{Objectives}

i. To study the experience of pain from the cancer patient with advanced disease;

ii. To identify the characteristics of pain;

iii. To identify influential factors to the experience of pain.

\section{Methodology}

During a quasi-experimental, longitudinal study, that evaluated the knowledge concerning pain, before and after the implementation of the educational program, as well as the ability to record the experience of pain in a diary, the following question was asked: "How would you describe your pain?" With three lines to write down the answer, the patients/caregivers described their experience of pain. The content of the answers was analysed, using the content analysis method and, by inference, categories and subcategories were identified.

\section{Subjects}

In the study enrroled 52 oncologic patients with advanced disease, who were attending in a day hospital, with medical appointments and symptomatic treatment or curative of second or third line.

\section{Results}

The pain was described by the cancer patient as incapacitating. As for characteristics, a grip-like pain emerges as the most frequent type of pain, followed by a sting-like and a stab-like pain. Most patients describe the pain as intense and ongoing, but it has also been described as unstable and acute. , $, 6,7$ The pain is personalized, and seen as something bad, treacherous, irritating, and horrible. It is considered as an enemy that wins over one's fatigue. ${ }^{6}$ It is related to other symptoms, demonstrating fatigue and general discomfort. It also interferes with communication, social and family relationships, sexuality and sex, which leads to deviation and isolation. ${ }^{6}$

The patient identifies factors that influence the experience of pain:

i. Factors that increase the pain and suffering, like loneliness, abandonment, feeling pitied by others, image changes, uncertainty about the future, and the prospect of death.7

ii. Factors that help in overcoming pain, like feeling loved, hope and faith. ${ }^{7}$

\section{Final thoughts}

The pain described by the cancer patient in an advanced stage is an intolerable pain that can lead to despair. Despite being a unique experience, there are some commonalities. The pain is characterized, personified, seen as an invincible enemy in the final stage. It interferes with communication and interpersonal relationships, prevents the intimate relationship between the couple and consumes the whole 
being. Regardless of the cause of pain, the fact that it exists confronts the patient to the significance of the situation and the prospect of death. The cancer patient with pain is suffering.

\section{Acknowledgements}

None.

\section{Conflicts of interest}

The authors declare that there is no conflict of interest.

\section{References}

1. https://www.iasp-pain.org/Taxonomy?navItemNumber=576\#Pain

2. Direcção Geral da Saúde. Programa nacional de controlo da dor. Circular normativa, Portugal: Springer; 2017. pp. 1-16.
3. Oldenmenger WH, Geerling JL, Mostovaya I, et al. A systematic review of the effectiveness of patient-based educational interventions to improve cancer-related pain. Cancer Treat Rev. 2017;13(63):96-103.

4. Tsigaroppoulos T, Mazaris E, Chatzidarellis E, et al. Problems faced by relatives caring for cancer patients at home. Int $J$ Nurs Pract. 2009;15(1):1-6.

5. Hughes ND, Closs SJ, Flemming K, et al. Supporting self-management of pain by patients with advanced cancer: views of palliative care professionals. Support Care Cancer. 2016;24(12):5049-5057.

6. Borneman T, Koczywas M, Sun V, et al. Effectiveness of a clinical intervention to eliminate barriers to pain and fatigue management in oncology. J Palliat Med. 2011;14(2):197-205.

7. Karen L Mark P, Mark P Jensen, M Elena Mendoza, et al. Psychological and behavioral approaches to cancer pain management. J Clin Oncol. 2014;32(16):1703-1711. 